\title{
What are the critical elements of sideline screening that can be used to establish the diagnosis of concussion? A systematic review
}

\author{
Jon Patricios, ${ }^{1,2}$ Gordon Ward Fuller, ${ }^{3}$ Richard Ellenbogen, ${ }^{4}$ Stanley Herring, ${ }^{4,5,6}$ \\ Jeffrey S Kutcher, ${ }^{7}$ Mike Loosemore, ${ }^{8}$ Michael Makdissi, ${ }^{9,10}$ Michael McCrea, ${ }^{11}$ \\ Margot Putukian, ${ }^{12}$ Kathryn J Schneider ${ }^{13}$
}

\begin{abstract}
- Additional material is published online only. To view please visit the journal online (http://dx.doi.org/10.1136/ bjsports-2016-097441)

For numbered affiliations see end of article.
\end{abstract}

\section{Correspondence to}

Dr Jon Patricios, Morningside Sports Medicine, PO Box 1267 Parklands, Cape Town 2121

South Africa; jpat@mweb.co.za

Accepted 6 February 2017 Published Online First 7 March 2017

\section{CrossMark}

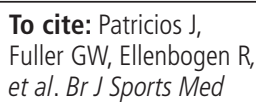

\begin{abstract}
Background Sideline detection is the first and most significant step in recognising a potential concussion and removing an athlete from harm. This systematic review aims to evaluate the critical elements aiding sideline recognition of potential concussions including screening tools, technologies and integrated assessment protocols. Data sources Bibliographic databases, grey literature repositories and relevant websites were searched from 1 January 2000 to 30 September 2016. A total of 3562 articles were identified.

Study selection Original research studies evaluating a sideline tool, technology or protocol for sports-related concussion were eligible, of which 27 studies were included.
\end{abstract}

Data extraction A standardised form was used to record information. The QUADAS-2 and NewcastleOttawa tools were used to rate risk of bias. Strength of evidence was assessed using the Grades of Recommendation, Assessment, Development and Evaluation Working Group system.

Data synthesis Studies assessing symptoms, the King-Devick test and multimodal assessments reported high sensitivity and specificity. Evaluations of balance and cognitive tests described lower sensitivity but higher specificity. However, these studies were at high risk of bias and the overall strength of evidence examining sideline screening tools was very low. A strong body of evidence demonstrated that head impact sensors did not provide useful sideline concussion information. Lowstrength evidence suggested a multimodal, multitimebased concussion evaluation process incorporating video review was important in the recognition of significant head impact events and delayed onset concussion. Conclusion In the absence of definitive evidence confirming the diagnostic accuracy of sideline screening tests, consensus-derived multimodal assessment tools, such as the Sports Concussion Assessment Tool, are recommended. Sideline video review may improve recognition and removal from play of athletes who have sustained significant head impact events. Current evidence does not support the use of impact sensor systems for real-time concussion identification.

\section{INTRODUCTION}

Despite a consensus definition of sports-related concussion (SRC) having been well elucidated, ${ }^{1}$ its immediate and accurate recognition in a clinical setting remains a challenge. ${ }^{2}$ Sustaining a SRC may increase the likelihood of incurring a subsequent head or musculoskeletal injury, ${ }^{3}$ and repeated concussions could be associated with long-term consequences such as persistent postconcussive symptoms, depression or neurodegenerative disorders. ${ }^{145}$ Early detection of suspected concussion and removal of the affected player will help prevent these potential adverse sequelae and facilitate further evaluation, management and safe return to play. This systematic review aims to evaluate the critical elements aiding off-field (commonly termed 'sideline') recognition of potential concussions. Specific objectives were to assess the diagnostic accuracy of existing clinical screening and diagnostic tools, determine the utility of technology in detecting SRC and assess integrated head injury assessment protocols currently used in professional collision sports.

\section{METHODS \\ Study design}

Expert consensus guidelines for the conduct of systematic reviews were followed, ${ }^{6-8}$ and a detailed protocol stating an a priori analysis plan was registered before data collection (PROSPERO 2016:CRD42016037831). The review question and inclusion/exclusion criteria are detailed in table 1. Online supplementary details on methodology, including a glossary of technical terms, are presented in the online supplementary file web appendix.

\section{Identification of evidence}

An extensive range of electronic information sources were examined including all major bibliographic databases, specialist sports medicine databases, grey literature repositories and relevant websites (see online supplementary web appendix for details). Additional information sources included forward and backward citation searching, author searching, reference checking and contact with experts. Search strategies for bibliographic databases were developed iteratively in conjunction with an information services specialist (University College London) and underwent external peer review (University of Sheffield).

Searches were conducted for original research published between 2000 (corresponding to the modern definition of concussion) and week 4, April 2016, and were otherwise unrestricted. Current awareness searches were conducted in MEDLINE 
Table 1 Review question and inclusion criteria

\begin{tabular}{|c|c|}
\hline \multicolumn{2}{|l|}{ Primary review question/aim } \\
\hline \multicolumn{2}{|c|}{$\begin{array}{l}\text { What are the critical elements of sideline screening that can be used to establish the } \\
\text { diagnosis of concussion or suspected concussion? }\end{array}$} \\
\hline \multicolumn{2}{|c|}{ Inclusion criteria } \\
\hline Population & $\begin{array}{l}\text { Athletes competing in sporting activity } \\
\text { and sustaining a non-trivial head impact } \\
\text { event (includes any nationality, gender, } \\
\text { age group or level of performance). }\end{array}$ \\
\hline Intervention/index tests & $\begin{array}{l}\text { Any sideline* screening assessment used } \\
\text { to detect suspected concussion following } \\
\text { sports-related significant head impact } \\
\text { events (including historical features, } \\
\text { symptoms, physical findings, clinical tests } \\
\text { or technologies) }\end{array}$ \\
\hline Outcome/reference standard & $\begin{array}{l}\text { Concussion, clinically diagnosed by a } \\
\text { registered medical practitioner. }\end{array}$ \\
\hline Study design & $\begin{array}{l}\text { Published or unpublished studies of any } \\
\text { research design. }\end{array}$ \\
\hline \multicolumn{2}{|l|}{ Exclusion criteria } \\
\hline Population & $\begin{array}{l}\text { Not related to sport, subjects }<13 \text { years, } \\
\text { animal studies }\end{array}$ \\
\hline Intervention/index tests & Non-sideline testing \\
\hline Outcome/reference standard & Concussion not examined \\
\hline Study design & Case reports \\
\hline \multicolumn{2}{|l|}{ Review subtopics/objectives } \\
\hline Sideline screening tests & $\begin{array}{l}\text { Characterise the diagnostic accuracy of } \\
\text { sideline clinical tests to detect suspected } \\
\text { SRC, including: } \\
\text { Symptoms and clinical signs } \\
\text { Balance tests } \\
\text { Oculomotor tests } \\
\text { Cognitive tests } \\
\text { Multimodal assessments (either joint } \\
\text { use of individual sideline tests or } \\
\text { multifaceted instruments) }\end{array}$ \\
\hline Technology & $\begin{array}{l}\text { Determine the utility of technology in the } \\
\text { detection of suspected SRC. }\end{array}$ \\
\hline $\begin{array}{l}\text { Integrated head injury assessment } \\
\text { protocols }\end{array}$ & $\begin{array}{l}\text { Evaluate integrated protocols for the } \\
\text { detection and management of SRC } \\
\text { currently used in professional collision } \\
\text { sports. }\end{array}$ \\
\hline
\end{tabular}

and Embase (week 4, September 2016) immediately prior to submission.

\section{Selection of evidence and data extraction}

Original research studies identified during searches were assessed in a four-stage process by teams of two independent reviewers. First, titles and abstracts were screened for relevance. Second, full-text articles were examined as required to assess eligibility. Third, studies meeting review inclusion criteria were classified into domains pertaining to: sideline screening tests (comprising subtopics of clinical signs and symptoms, balance tests, oculomotor assessments, cognitive tests and multimodal testing strategies); technology; and professional sports-specific head injury assessment protocols (defined in table 1). Finally, data extraction was performed separately for eligible studies within each subtopic. A single unblinded reviewer extracted information on study characteristics, methodology and results using a standardised data extraction form; and a second reviewer independently checked data for consistency and accuracy. In cases of disagreement at any stage, consultation with a third author was planned, with consensus derived by arbitration.

\section{Risk of bias assessment}

Included studies were assessed for risk of bias using peer-reviewed critical appraisal checklists appropriate to study design. The QUDAS-2 tool was used for diagnostic accuracy studies.' Observational studies were evaluated using the Newcastle-Ottawa scale. ${ }^{6}$ A single unblinded reviewer within each subgroup team assessed risk of bias, with a second reviewer independently checking the assessment for validity. Any disagreement between reviewers was resolved by consensus and consultation with a third author with expertise in epidemiology and critical appraisal.

\section{Data synthesis, statistical analyses and assessment of overall quality of evidence}

Data synthesis and statistical analysis were performed separately for eligible studies within each subtopic. Results are presented descriptively with reported point estimates and 95\% CIs and summarised graphically using Forest plots. ${ }^{10}$ Heterogeneity was assessed using the $\mathrm{I}^{2}$ statistic. ${ }^{11}$ A narrative synthesis was prespecified in the event that clinically and methodologically homogenous studies at low risk of bias were not identified. References were managed in EndNote (Clarivate Analytics, Berkeley California, USA), extracted data were collated in Excel 2013, and Forest plots were formulated using Meta-DiSc V.1.4 (University of Birmingham, Birmingham, UK). The overall quality of evidence for each outcome was assessed using the consensus Grades of Recommendation, Assessment, Development and Evaluation Working Group (GRADE) approach. ${ }^{12}$ GRADE is a systematic method of assessing quality of evidence and strength of recommendations taking into account methodological flaws, consistency of results, generalisability of findings and the effectiveness of treatments. A clinical diagnosis of concussion was the primary outcome for each domain.

\section{RESULTS}

\section{Study selection}

A total of 3562 citations were screened for eligibility, with the full text of 198 articles retrieved for detailed evaluation. During full text examination, 27 studies were found meeting review inclusion criteria: sideline screening assessment (21 studies); integrated diagnostic protocols (1 study) and technology (5 studies). Figure 1 describes the selection of studies in detail.

\section{Sideline screening tests}

\section{Characteristics of included studies}

Twenty-one studies met review inclusion criteria and reported interpretable data on the diagnostic accuracy of screening tests, either alone or in combination, to identify suspected SRC. Characteristics of the included studies examining sideline assessments are summarised in table 2 .

\section{Risk of bias}

Assessment of risk of bias is summarised according to QUDAS-2 domains in table 3 and figure 2. Overall risk of bias was high or unclear for all included studies. The predominant limitation was the use of a 'two-gate' study design using healthy controls, which is known to overestimate estimates of test performance. ${ }^{1314}$ Other systematic errors included delayed index testing, inaccurate reference standard assessment by a 
non-medically trained outcome assessors, and test and diagnostic review, incorporation and attrition biases. Detailed risks of bias evaluations are presented in the online y supplementary web appendix.

\section{Results}

The diagnostic accuracy of sideline assessments for detecting suspected concussion is summarised in figure 3. Studies examining symptoms, the King-Devick (KD) test and multimodal assessments reported relatively good sensitivity and specificity. Evaluations of balance and cognitive tests described lower sensitivity, but relatively good specificity. However, results were imprecise and heterogeneous for all types of sideline assessments, in addition to the concerns regarding the internal validity. The overall quality of evidence according to GRADE criteria was very low for all classes of sideline tests based on serious concerns regarding inconsistency, imprecision and risk of bias. Detailed results and evaluation of overall quality of evidence for individual tests are provided in the online supplementary web appendix.

\section{Technology}

Five studies met review inclusion criteria and reported interpretable data on the use of a technology in sideline screening for SRC, examining head impact sensors (four studies) and sideline video review (one study). ${ }^{15-19}$ Overall risk of bias was low for all studies. Reported results indicated that no clinically significant relationship existed between impact magnitude, or location, and concussion $(\mathrm{p}>0.05)$. Fuller et $a l^{16}$ reported that sideline video review contributed to identification of $61.5 \%$ of significant

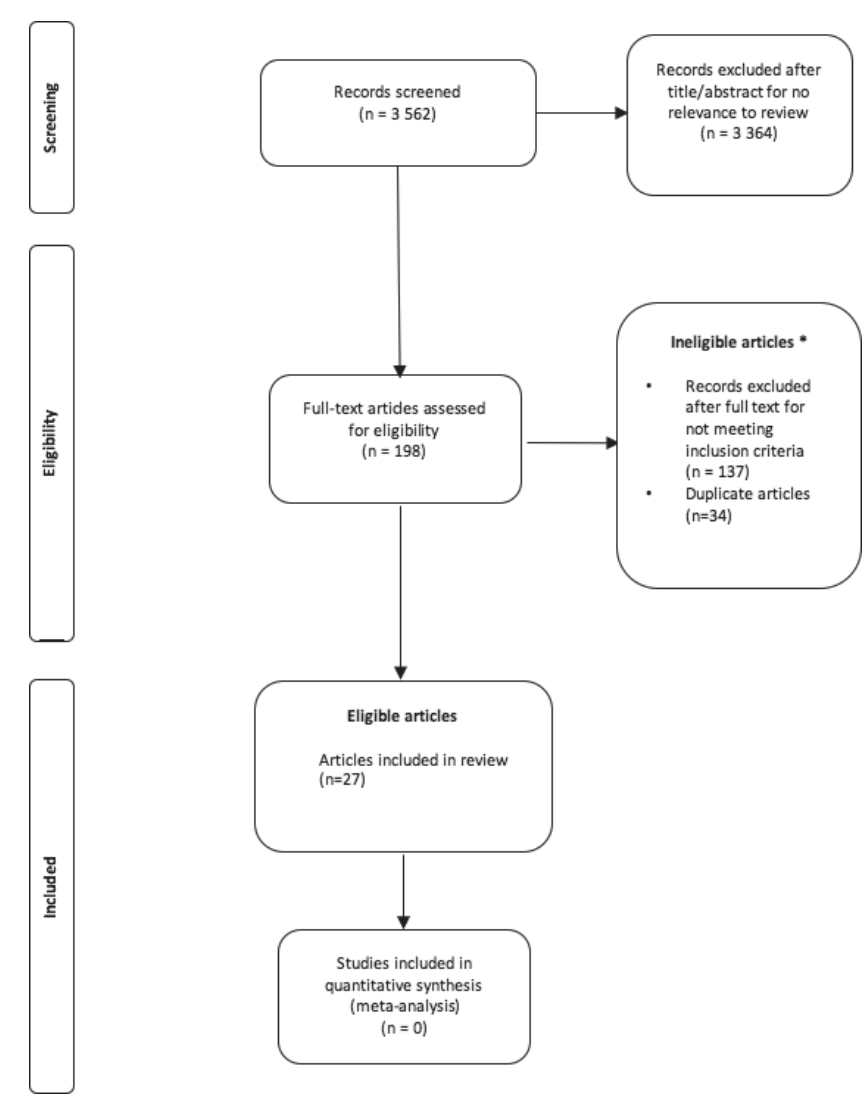

Figure 1 Flow of identification, screening, eligibility and inclusion criteria for the literature review of sideline diagnosis of concussion. head impact events and influenced sideline evaluation in $20.4 \%$ of cases. The overall GRADE quality of evidence was rated as high for head impact sensors and low for sideline video review. Table 4 summarises the characteristics, risk of bias and main results of included technology studies. Further details on risk of bias and GRADE ratings are provided in the online supplementary web appendix.

\section{Integrated head injury assessment protocols}

No experimental or comparative effectiveness research was identified evaluating the performance of alternative head injury assessment protocols. However, a single study at low risk of bias was retrieved which evaluated a comprehensive system used at the elite level in Rugby Union. ${ }^{16}$ The major finding was the importance of a multimodal, multitime-based concussion evaluation process incorporating video review to identify significant head impact events and delayed onset concussion. The overall GRADE quality of evidence was rated low, secondary to imprecision and potential inconsistency. Further details on existing integrated head injury assessment protocols in professional sports, and the characteristics of Fuller et al are provided in the online supplementary web appendix.

\section{DISCUSSION}

\section{Summary of key findings}

Studies examining symptoms, the KD test and multimodal assessments reported high sensitivity and specificity. Evaluations of balance and cognitive tests described lower sensitivity, but good specificity. However, the overall strength of evidence examining sideline screening tools was of very low quality secondary to high risk of bias, and imprecise and heterogeneous diagnostic accuracy estimates. Studies examining technology provided a high (head impact sensors) or low (video review) strength body of evidence. Head impact sensors did not provide useful information. Conversely, a multimodal, multitime-based concussion evaluation process incorporating video review appeared to be important for the identification of significant head impact events and the delayed onset concussion.

\section{Interpretation}

A meta-analysis was not performed due to the absence of studies at low risk of bias and marked heterogeneity; in accordance with the prespecified analysis plan, a narrative synthesis was therefore conducted. Interestingly, no obvious patterns were evident between study results and design characteristics including sample size, setting, performance level, sport or risk of bias. This may be due to the inherent generalisability of findings, but could also be explained by biases operating in different directions and to varying magnitudes across different studies.

Notwithstanding the high risk of systematic error, a wide range of settings, sports and age groups were investigated in eligible studies suggesting good external validity of findings. However, in addition to information on diagnostic accuracy, the feasibility, cost and acceptability of alternative sideline tests may be important in applying these results to different settings. The availability of baseline data, testing environment and influence of the athlete-physician relationship could also affect generalisability. Importantly, in lower levels of competition where medical staff may be limited, an alternative 'recognise and remove' approach is recommended, with exclusion of the sideline screening stage, and immediate and permanent removal from any further participation when there is any suspicion of concussion. $^{120}$ 
Table 2 Characteristics of included studies examining sideline screening assessments

\begin{tabular}{|c|c|c|c|c|c|c|c|c|c|}
\hline Study & Setting & $\begin{array}{l}\text { Study } \\
\text { design }\end{array}$ & $\begin{array}{l}\text { Sample } \\
\text { size } \\
\text { (n) }\end{array}$ & Sport(s) & Level & $\begin{array}{l}\text { Mean age } \\
\text { (years } \pm \text { SE) }\end{array}$ & $\begin{array}{l}\text { Gender } \\
(\% \\
\text { male })\end{array}$ & Index test(s) & Reference standard \\
\hline $\begin{array}{l}\text { Maddocks } \\
\text { et } a l^{33}\end{array}$ & Australia & PCS & 56 & $\begin{array}{l}\text { Australian } \\
\text { football }\end{array}$ & Professional & NR & 100 & $\begin{array}{l}\text { Individual symptoms, Maddocks } \\
\text { questions }\end{array}$ & Clinical diagnosis \\
\hline $\begin{array}{l}\text { McCrory } \\
\text { et } a l^{34}\end{array}$ & Australia & PCS & 303 & $\begin{array}{l}\text { Australian } \\
\text { football }\end{array}$ & Professional & NR & 100 & Individual symptoms & Clinical diagnosis \\
\hline Barr and $\mathrm{McCrea}{ }^{35}$ & USA & PCS & 118 & $\begin{array}{l}\text { American } \\
\text { football }\end{array}$ & $\begin{array}{l}\text { Varsity } \\
\text { high school }\end{array}$ & 18.1 (NR) & NR & SAC & Clinical diagnosis \\
\hline Erlanger et $a l^{36}$ & USA & PCS & 47 & $\begin{array}{l}\text { American } \\
\text { football, } \\
\text { ice hockey, } \\
\text { field hockey, } \\
\text { wrestling, } \\
\text { soccer, } \\
\text { basketball }\end{array}$ & $\begin{array}{l}\text { School } \\
\text { adolescents }\end{array}$ & $\begin{array}{l}17.6(S D \\
2.23)\end{array}$ & 57 & Individual symptoms & NR \\
\hline $\mathrm{McCrea}^{37}$ & USA & PCS & 118 & $\begin{array}{l}\text { American } \\
\text { football }\end{array}$ & $\begin{array}{l}\text { Varsity } \\
\text { high school }\end{array}$ & $19.8 \pm 1.3$ & NR & SAC & Clinical diagnosis \\
\hline McCrea et $a \beta^{38}$ & USA & PCS & 91 & $\begin{array}{l}\text { American } \\
\text { football }\end{array}$ & $\begin{array}{l}\text { Varsity } \\
\text { high school }\end{array}$ & $17.5 \pm 2.1$ & NR & SAC & Clinical diagnosis \\
\hline McCrea et $a \beta^{39}$ & USA & PCS & 150 & $\begin{array}{l}\text { American } \\
\text { football }\end{array}$ & $\begin{array}{l}\text { Collegiate } \\
\text { adults }\end{array}$ & $\begin{array}{l}20.04(S D \\
1.36)\end{array}$ & 100 & GSC, BESS, SAC & Clinical diagnosis \\
\hline Echlin et $a l^{40}$ & USA & PCS & 67 & Ice hockey & $\begin{array}{l}\text { Junior } \\
\text { adolescents }\end{array}$ & $18.2 \pm 1.2$ & $100 \%$ & BESS, SAC & $\begin{array}{l}\text { Clinical diagnosis + } \\
\text { SCAT } 2\end{array}$ \\
\hline Galetta et $a l^{41}$ & USA & PCS & 39 & $\begin{array}{l}\text { Boxing, mixed } \\
\text { martial arts }\end{array}$ & Amateur adult & 24 & 97 & KD & MACE \\
\hline Galetta et $a l^{42}$ & USA & PCS & 219 & $\begin{array}{l}\text { American } \\
\text { football, } \\
\text { soccer, } \\
\text { basketball }\end{array}$ & $\begin{array}{l}\text { Collegiate } \\
\text { athletics }\end{array}$ & $20.3 \pm 1.4$ & 83 & KD & Clinical diagnosis \\
\hline Barr et $a l^{43}$ & USA & PCS & 90 & $\begin{array}{l}\text { American } \\
\text { football }\end{array}$ & $\begin{array}{l}\text { High school, } \\
\text { collegiate }\end{array}$ & NR & 100 & CSI, SAC, BESS & Clinical diagnosis \\
\hline King et $a l^{44}$ & $\mathrm{NZ}$ & PCS & 50 & Rugby league & Amateur adult & $22.4 \pm 4.1$ & 100 & KD & SCAT 2 \\
\hline Galetta et $a l^{45}$ & USA & PCS & 27 & Ice hockey & Professional & $25 \pm 5$ & 100 & $\mathrm{KD}, \mathrm{SAC}$ & SCAT 2 \\
\hline Dhawan et al ${ }^{46}$ & USA & PCS & 141 & Hockey & $\begin{array}{l}\text { High school } \\
\text { athletics }\end{array}$ & NR & NR & KD & NR \\
\hline Leong et $a l^{47}$ & USA & PCS & 34 & Boxing & Amateur adult & $25.8 \pm 8.3$ & 85 & KD & MACE \\
\hline Fuller et $a l^{21}$ & $\begin{array}{l}\text { UK, RSA, } \\
\text { France }\end{array}$ & PCS & 165 & Rugby union & $\begin{array}{l}\text { Professional } \\
\text { adults }\end{array}$ & NR & 100 & $\begin{array}{l}\text { PSACA1 tool: Maddocks questions, } \\
\text { symptoms checklist, mental status } \\
\text { assessment, tandem stance test }\end{array}$ & $\begin{array}{l}\text { Clinical diagnosis + } \\
\text { SCAT } 3\end{array}$ \\
\hline Galetta et $a{ }^{48}$ & USA & PCS & 243 & $\begin{array}{l}\text { Ice hockey, } \\
\text { lacrosse, } \\
\text { athletics }\end{array}$ & $\begin{array}{l}\text { Amateur youth, } \\
\text { collegiate } \\
\text { athletics }\end{array}$ & $\begin{array}{l}\text { Youths: } \\
11 \pm 3 \\
\text { adults: } \\
20 \pm 1\end{array}$ & $\begin{array}{l}\text { Youths: } \\
84 \\
\text { Adults: } \\
74\end{array}$ & $\mathrm{KD}$, timed tandem gait, SAC & Clinical diagnosis \\
\hline Leong et $a l^{49}$ & USA & PCS & 127 & $\begin{array}{l}\text { American } \\
\text { football, } \\
\text { basketball }\end{array}$ & $\begin{array}{l}\text { Collegiate } \\
\text { athletics }\end{array}$ & $19.6 \pm 1.2$ & 94 & KD & Modified SCAT 2 \\
\hline Marinides et $a l^{50}$ & USA & RCS & 217 & $\begin{array}{l}\text { American } \\
\text { football, } \\
\text { lacrosse, } \\
\text { soccer }\end{array}$ & $\begin{array}{l}\text { Collegiate } \\
\text { athletics }\end{array}$ & NR & 70 & $\mathrm{KD}, \mathrm{BESS}, \mathrm{SAC}$ & Clinical diagnosis \\
\hline Putukian et $a P^{1}$ & USA & PCS & 263 & $\begin{array}{l}\text { American } \\
\text { football, rugby } \\
\text { union, sprint } \\
\text { football, crew }\end{array}$ & $\begin{array}{l}\text { Collegiate } \\
\text { adults }\end{array}$ & $\begin{array}{l}20.33(S D \\
1.74)\end{array}$ & $67 \%$ & $\begin{array}{l}\text { SCAT2 symptom checklist, modified } \\
\text { BESS, SAC, SCAT2 }\end{array}$ & Clinical diagnosis \\
\hline Seidman et $a l^{52}$ & USA & PCS & 337 & $\begin{array}{l}\text { American } \\
\text { football }\end{array}$ & $\begin{array}{l}\text { High school } \\
\text { athletics }\end{array}$ & $15.4 \pm 1.3$ & 100 & KD & SCAT 3 \\
\hline
\end{tabular}

BESS, Balance Error Scoring System; CSI, Concussion Symptom Inventory; GSC, Graded Symptom Checklist; KD, King-Devick; MACE, Military Acute Concussion Evaluation; NR, not reported; NZ, New Zealand; PCS, prospective cohort study; RCS, retrospective cohort study; RSA, Republic of South Africa; SAC, Standardised Assessment of Concussion; SCAT, Sports Concussion Assessment Tool.

A key concept in sideline assessment is the rapid screening for a suspected concussion, rather than the definitive diagnosis of a head injury. Players manifesting clear on-field observable signs, such as loss of consciousness, ataxia, tonic posturing or post-traumatic seizures, can immediately be diagnosed with a concussion and removed from sporting participation. Athletes with the possibility of suspected concussion following a significant head impact event can alternatively proceed to sideline 
Table 3 Summary of risk of bias across included sideline screening studies

\begin{tabular}{|c|c|c|c|c|c|}
\hline \multirow[b]{2}{*}{ Study } & \multicolumn{5}{|c|}{ Risk of bias } \\
\hline & $\begin{array}{l}\text { Patient } \\
\text { selection }\end{array}$ & $\begin{array}{l}\text { Index } \\
\text { test }\end{array}$ & $\begin{array}{l}\text { Reference } \\
\text { standard }\end{array}$ & $\begin{array}{l}\text { Flow and } \\
\text { timing }\end{array}$ & Overall \\
\hline Maddocks et $a l^{33}$ & $\mathrm{H}$ & $\mathrm{L}$ & $\mathrm{L}$ & L & H \\
\hline Barr and $\mathrm{McCrea}{ }^{35}$ & $\mathrm{H}$ & $?$ & $\mathrm{H}$ & L & $\mathrm{H}$ \\
\hline McCrory et $a l^{34}$ & H & $?$ & L & L & $\mathrm{H}$ \\
\hline McCrea ${ }^{37}$ & $\mathrm{H}$ & $?$ & $\mathrm{H}$ & L & $\mathrm{H}$ \\
\hline McCrea et $a^{\beta 8}$ & H & $?$ & $H$ & L & $\mathrm{H}$ \\
\hline Erlanger et $a^{36}$ & $\mathrm{H}$ & $?$ & $?$ & L & $\mathrm{H}$ \\
\hline McCrea et al $\left.\right|^{39}$ & H & H & $H$ & H & $\mathrm{H}$ \\
\hline Echlin et a ${ }^{40}$ & $\mathrm{H}$ & H & $\mathrm{H}$ & $\mathrm{H}$ & $\mathrm{H}$ \\
\hline Galetta et $a l^{41}$ & L & $?$ & $?$ & H & $H$ \\
\hline Galetta et $a^{42}$ & $\mathrm{H}$ & L & $\mathrm{H}$ & L & $\mathrm{H}$ \\
\hline Barr et $a l^{43}$ & H & H & $\mathrm{H}$ & L & $H$ \\
\hline King et $a l^{44}$ & L & $?$ & $?$ & $?$ & $?$ \\
\hline Galetta et $a l^{45}$ & H & $?$ & $?$ & L & $H$ \\
\hline Dhawan et a $\left.\right|^{46}$ & $\mathrm{H}$ & $?$ & $?$ & L & $H$ \\
\hline Fuller et $a^{21}$ & L & L & $H$ & L & H \\
\hline Leong et al/7 & L & L & L & H & $H$ \\
\hline Galetta et $a l^{48}$ & H & $?$ & $?$ & H & $H$ \\
\hline Leong et $a l^{49}$ & $\mathrm{H}$ & L & $\mathrm{H}$ & L & $\mathrm{H}$ \\
\hline Marinides et $a l^{50}$ & H & $?$ & $?$ & H & $\mathrm{H}$ \\
\hline Putukian et $a l^{51}$ & $\mathrm{H}$ & H & L & $\mathrm{H}$ & $\mathrm{H}$ \\
\hline Seidman et $a l^{52}$ & H & H & L & H & H \\
\hline
\end{tabular}

$\mathrm{H}$, high; L, low; ?, unclear risk of bias.

screening, with a later definitive diagnostic evaluation. Clearly, to allow sufficient time and a suitable environment for testing, this should occur away from the sporting environment, and may necessitate a temporary athlete interchange. The importance of off-field testing is exemplified by findings in professional Rugby where the number of players with confirmed concussion returning to play following their head injury dropped from 56\% to $13 \%$ following the introduction of the Pitchside Suspected Concussion Assessment that superseded an 'on-the-field-andon-the run' approach. ${ }^{21}$

Elite contact and collision sports are played at a fast pace in a disorganised environment, where the view of medical staff may be obscured, challenging the evaluation of head impact events. Video review appeared to be helpful in identifying both observable signs of concussion and cases of possible suspected concussion where further assessment off-field is beneficial. Furthermore, evolving and delayed onset concussions have been well described, ${ }^{162}$ highlighting the importance of careful follow-up after a significant head impact, regardless of a negative sideline screening test or early diagnostic evaluation. Consequently, implementation of systematic head injury assessment protocols appears to improve detection and management of the full spectrum of SRC.

Concussion can manifest as a diverse range of somatic, cognitive, behavioural or emotional symptoms; and/or physical signs such as vestibulo-ocular deficits, loss of consciousness and ataxia. ${ }^{1}$ It would therefore be expected ex ante that multimodal assessments, evaluating several of these domains, are necessary to maximise detection of different subtypes of SRC. However, with simultaneous testing a net gain in sensitivity usually occurs at the expense of a net loss in specificity. ${ }^{23}$ Interestingly, included multimodal assessment studies reported both high sensitivity and specificity which could suggest either an optimal combination of

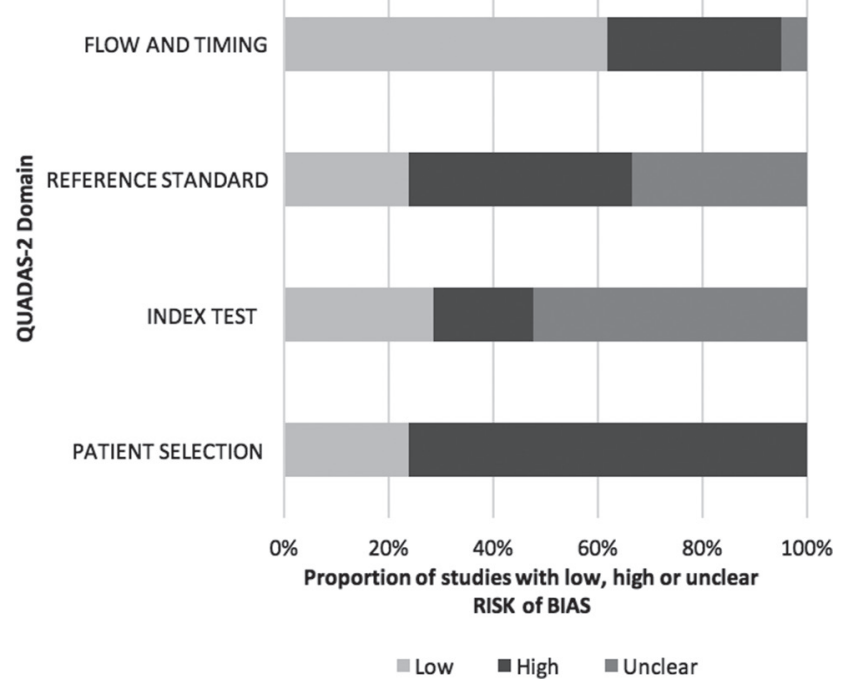

Figure 2 Summary of risk of bias in included studies examining sideline screening.

tests, or could reflect study biases. Given the absence of definitive evidence on the performance of sideline tests, expert consensus opinion is necessary to guide practice and strongly recommends the use of a multimodal assessment tool, of which the Sports Concussion Assessment Tool (SCAT; now in its 4th version) is the most established, well developed and studied. ${ }^{24}$

It is important to note that the pretest probability of concussion will strongly influence the performance of sideline screening tests. ${ }^{25}$ In settings with high prevalence of concussion, or high test thresholds, the negative predictive value of sideline tests will fall. High sensitivity and specificity would consequently be necessary to ensure the detection of a satisfactory proportion of cases. Conversely, indiscriminate testing, with a lower pretest probability of concussion, would result in higher negative predictive values, but worsening numbers of false positives. Such a safety first approach might be preferred in non-elite settings.

\section{Consistency with other studies or reviews}

There have been a large number of narrative reviews, position statements and editorials that have previously examined the role of sideline screening tests or technology in the detection of SRC. Although these articles are inherently limited by a lack of defined inclusion criteria, systematic search strategies and transparent risk of bias assessment, their conclusions are broadly consistent with the current systematic review. For example, Eckner et $a l^{26}$ stated that 'multiple assessment tools are available, with no single tool showing clear superiority. Many tools remain based more on expert opinion than rigorous scientific evaluation.'

Six related systematic reviews were also identified during the literature searches, comprising examination of symptom checklists, ${ }^{27}$ SCAT 2/3, ${ }^{28}$ Balance Error Scoring System, ${ }^{29} \mathrm{KD}_{\text {test }}{ }^{30} 31$ and sideline testing in general. ${ }^{32}$ Although the review questions were not directly comparable, including delayed non-sideline testing and additional examination of test reliability, similar studies were often included and conclusions concurred with the current study in Alla, ${ }^{27}$ Yengo-Khan, ${ }^{28}$ Bell $^{29}$ and Hunt. ${ }^{30}$ For example, Alla ${ }^{27}$ noted that 'There is little information available on the derivation or psychometric properties (eg, sensitivity, reliability, etc) of the various symptom scales', and Yengo$\mathrm{Khan}^{28}$ observed that 'the sensitivity and specificity of the 
Oculomotor Tests

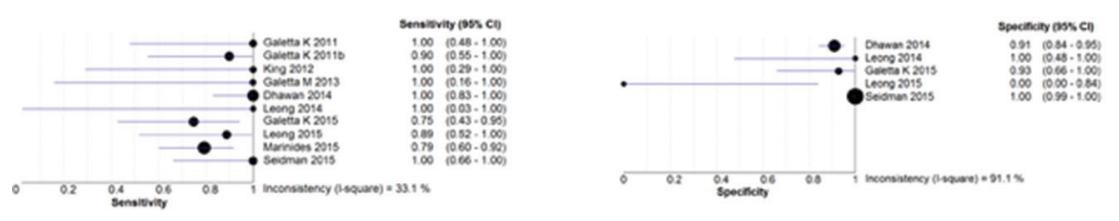

Balance Tests
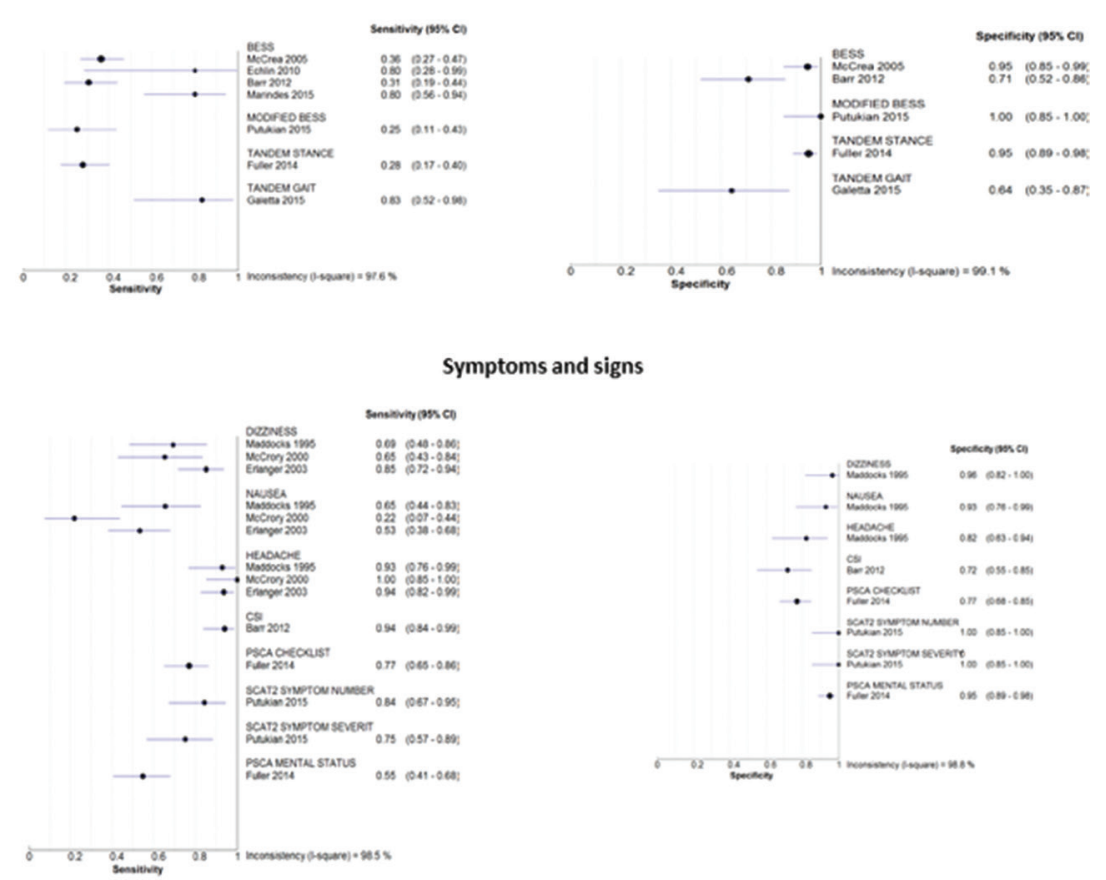

Cognitive Tests
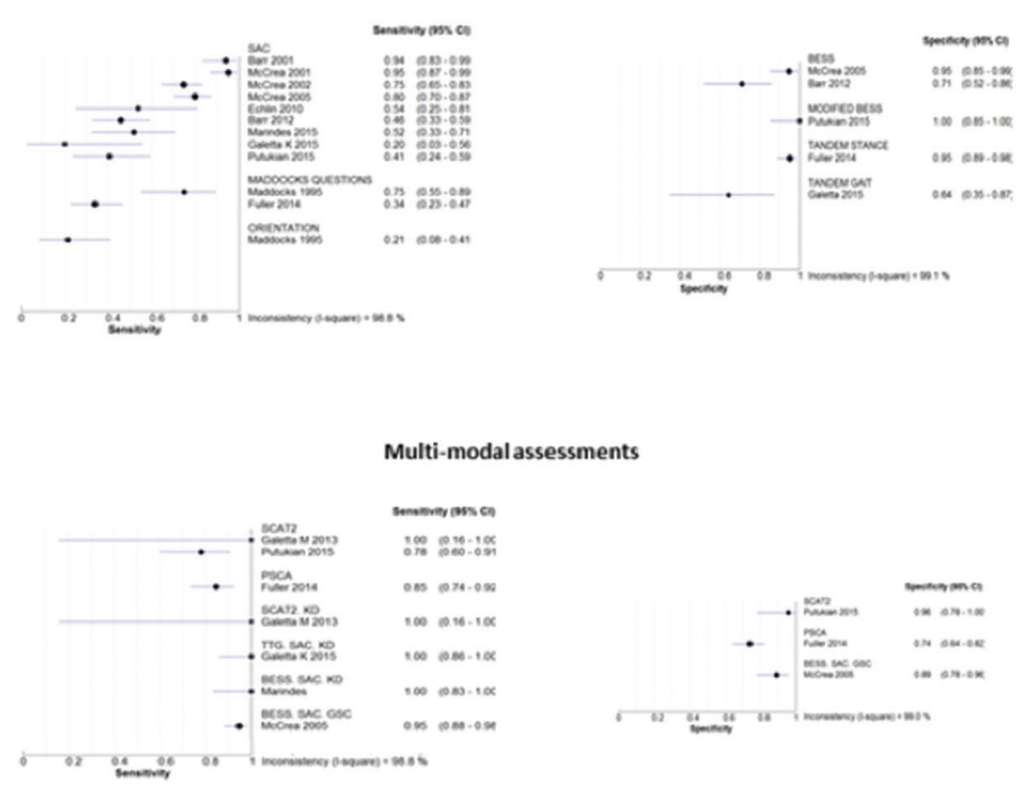

Figure 3 Diagnostic accuracy of sideline screening tests for suspected sports-related concussion.

SAC has been reported sparsely.' Conversely, in contrast to the current findings, Galetta ${ }^{31}$ and King ${ }^{32}$ concluded that the KD test can successfully identify SRC on the sideline. This divergent opinion is explained by the absence of any risk of bias assessment for constituent studies included in their reviews, resulting in the KD test being interpreted as having high sensitivity and specificity whereas the quality of evidence presented did not justify this. 
Table 4 Characteristics, risk of bias and primary findings of included technology studies

\begin{tabular}{|c|c|c|c|c|c|c|c|c|c|c|}
\hline Study & Setting & Design & $\begin{array}{l}\text { Sample } \\
\text { size } \\
\text { (n) }\end{array}$ & Sport(s) & Level & $\begin{array}{l}\text { Mean age } \\
\text { (years } \pm S E \text { ) }\end{array}$ & Technology & $\begin{array}{l}\text { Risk of bias/ } \\
\text { evidence } \\
\text { level }\end{array}$ & $\begin{array}{l}\text { Applicability } \\
\text { concerns }\end{array}$ & Primary finding(s) \\
\hline Guskiewicz et al ${ }^{18}$ & USA & PCS & 81 & & high school & $20.2 \pm 1.8$ & HITS & Low & Low & $61.5 \%$ sensitivity for concussion* \\
\hline Mihalak et al ${ }^{19}$ & USA & PCS & 102 & $\begin{array}{l}\text { American } \\
\text { football }\end{array}$ & Collegiate & $19.6 \pm 1.6$ & HITS & Unclear & Low & PPV of $0.35 \%$ for concussiont \\
\hline Greenwald et al ${ }^{17}$ & USA & PCS & 449 & $\begin{array}{l}\text { American } \\
\text { football }\end{array}$ & High school & NR & HITS & Low & Low & PPV of $0.3 \%$ for concussion* \\
\hline Broglio et $a l^{15}$ & USA & PCS & 78 & $\begin{array}{l}\text { American } \\
\text { football }\end{array}$ & High school & $16.7 \pm 0.8$ & HITS & Low & Low & PPV of $13.4 \%$ for concussion $\neq$ \\
\hline Fuller et $a^{16}$ & UK & PCS & 49 & $\begin{array}{l}\text { Rugby } \\
\text { union }\end{array}$ & Professional & $\begin{array}{l}26.5 \text { (SD } \\
3.5)\end{array}$ & $\begin{array}{l}\text { Sideline } \\
\text { video review }\end{array}$ & Low & Low & $\begin{array}{l}\text { Contributed to identification of } \\
61 \% \text { of significant head impact } \\
\text { events }\end{array}$ \\
\hline
\end{tabular}

${ }^{*}$ Head impact threshold: linear acceleration $>98.9 \mathrm{~g}$.

†Threshold: linear acceleration $>80 \mathrm{~g}$.

†Threshold: $>5582.3 \mathrm{rad} / \mathrm{s}^{2} \pm 96.1 \mathrm{~g}$ linear acceleration \pm front/side/top impact.

HITS, head impact telemetry system; NR, not reported; PCS, prospective cohort study; PPV, positive predictive value.

\section{Implications for research}

There is an absence of valid research confirming the diagnostic accuracy and impact on improving outcomes of currently used sideline screening tests. Adequately powered diagnostic accuracy studies are therefore recommended that enrol a representative sample of athletes with suspected concussion following non-trivial head impact events. Ideally, once the diagnostic accuracy and optimal threshold of sideline tests have been confirmed, comparative effectiveness studies would investigate whether important outcomes are improved. Further research is also recommended to investigate the impact of integrated head injury assessment protocols and sideline video review for the evaluation of head impact events. Further research could usefully examine novel sideline screening tests such as reaction times, or investigate the utility of tablet software applications as an adjunct to sideline concussion screening.

\section{Review limitations}

There are a number of potential methodological weaknesses which could limit the validity of this systematic review. Because of time constraints, hand searching of journals and conference proceedings was not performed and regional bibliographic databases were not included raising the potential for publication bias. Decisions on study relevance, information gathering and validity were unblinded and potentially could have been influenced by preformed opinions. Furthermore, data extraction and risk of bias assessment were not performed in duplicate (ie, two truly independent reviews), with the second reviewer checking the assessment of the first reviewer. Finally, assessment of reference standard bias was challenged by the lack of a convincing diagnostic gold standard.

\section{CONCLUSIONS}

Based on this systematic review of the literature, an evidencebased recommendation for any individual screening test or protocol is not possible. The recognition of suspected concussion is therefore best approached using multimodal testing guided via expert consensus. The SCAT currently represents the most well-established and rigorously developed instrument available for sideline assessment. The addition of video review could potentially offer a promising approach to improve identification and evaluation of significant head impact events, and a multitime-based concussion evaluation process appears to be important to detect delayed onset SRC. The KD test shows promise as a sideline screening test but requires adequately powered diagnostic accuracy studies which avoid a two-gate design with healthy controls, and enrols a representative sample of athletes with suspected concussion. Collaboration between sporting codes to rationalise multimodal diagnostic sideline protocols may help facilitate more efficient application and monitoring. Current evidence does not support the use of impact sensor systems for real-time concussion screening.

\section{Author affiliations}

${ }^{1}$ Section Sports Medicine, Faculty of Health Sciences, University of Pretoria, Pretoria, South Africa

${ }^{2}$ Department of Emergency Medicine, Faculty of Health Sciences, University of the Witwatersrand, Johannesburg, South Africa

${ }^{3}$ Centre for Urgent and Emergency Care Research, School of Health and Related Research, University of Sheffield, Sheffield, UK

${ }^{4}$ Department of Neurological Surgery, University of Washington, Seattle, Washington, USA

${ }^{5}$ Departments of Rehabilitation Medicine, University of Washington, Seattle, Washington, USA

${ }^{6}$ Orthopedics and Sports Medicine, University of Washington, Seattle, Washington, USA

${ }^{7}$ The Sports Neurology Clinic at the CORE Institute, Brighton, Michigan, USA

${ }^{8}$ Institute of Sport Exercise and Health, University College London, London, UK

${ }^{9}$ Florey Institute of Neuroscience and Mental Health, Austin Campus, Melbourne Brain Centre, Heidelberg, Victoria, Australia

${ }^{10}$ Olympic Park Sports Medicine Centre, Melbourne, Victoria, Australia

${ }^{11}$ Department of Neurosurgery, Medical College of Wisconsin, Milwaukee, Wisconsin, USA

${ }^{12}$ Director of Athletic Medicine, Princeton University, Princeton, New Jersey, USA ${ }^{13}$ Sport Injury Prevention Research Centre, Faculty of Kinesiology, University of Calgary, Alberta, Canada

Competing interests JP received travel subsidies for conferences from South African Rugby and World Rugby. GWF is funded by the National Institute for Health Research and received travel funding from World Rugby. RE, SH, JSK, $\mathrm{ML}, \mathrm{MM}, \mathrm{MP}$ have no competing interests to decalre. MM received travel and accommodation costs. KJS has received speaking honoraria for presentations at scientific meetings.

Provenance and peer review Not commissioned; externally peer reviewed.

(C) Article author(s) (or their employer(s) unless otherwise stated in the text of the article) 2017. All rights reserved. No commercial use is permitted unless otherwise expressly granted.

\section{REFERENCES}

1 McCrory P, Meeuwisse WH, Aubry M, et al. Consensus statement on concussion in sport: the 4th International Conference on Concussion in Sport held in Zurich, November 2012. Br J Sports Med 2013;47:250-8.

2 Helmy A, Agarwal M, Hutchinson PJ. Concussion and sport. BMJ 2013;347:f5748. 
3 Herman D. C, Zaremski JL, Vincent HK, et al. Effect of neurocognition and concussion on musculoskeletal injury risk. Curr Sports Med Rep 2015;14:194-9.

4 Guskiewicz KM, Marshall SW, Bailes J, et al. Association between recurrent concussion and late-life cognitive impairment in retired professional football players. Neurosurgery 2005;57:719-26.

5 McKee AC, Cantu RC, Nowinski CJ, et al. Chronic traumatic encephalopathy in athletes: progressive tauopathy after repetitive head injury. J Neuropathol Exp Neurol 2009:68:709-35.

6 Higgins J, Green SP. Cochrane handbook for systematic reviews of interventions. Wiley-Blackwell: Oxford, 2008.

7 Liberati A, Altman DG, Tetzlaff J, et al. The PRISMA statement for reporting systematic reviews and meta-analyses of studies that evaluate healthcare interventions: explanation and elaboration. BMJ 2009;339:b2700.

8 Leeflang MM, Deeks JJ, Gatsonis C, et al; Cochrane Diagnostic Test Accuracy Working Group. Systematic reviews of diagnostic test accuracy. Ann Intern Med 2008;149:889-97.

9 Whiting PF, Rutjes AW, Westwood ME, et al; QUADAS-2 Group. QUADAS-2: a revised tool for the quality assessment of diagnostic accuracy studies. Ann Intern Med 2011;155:529-36.

10 Lewis S, Clarke M. Forest plots: trying to see the wood and the trees. BMJ 2001;322:1479-80

11 Higgins JP, Thompson SG, Deeks JJ, et al. Measuring inconsistency in meta-analyses. BMJ 2003;327:557-60.

12 Schünemann HJ, Schünemann AH, Oxman AD, et al; GRADE Working Group. Grading quality of evidence and strength of recommendations for diagnostic tests and strategies. Bmj 2008;336:1106-10.

13 Rutjes AW, Reitsma JB, Vandenbroucke JP, et al. Case-control and two-gate designs in diagnostic accuracy studies. Clin Chem 2005;51:1335-41.

14 Lijmer JG, Mol BW, Heisterkamp S, et al. Empirical evidence of design-related bias in studies of diagnostic tests. JAMA 1999;282:1061-6.

15 Broglio SP, Schnebel B, Sosnoff JJ, et al. Biomechanical properties of concussions in high school football. Med Sci Sports Exerc 2010;42:2064-71.

16 Fuller CW, Fuller GW, Kemp SP, et al. Evaluation of World Rugby's concussion management process: results from Rugby World Cup 2015. Br J Sports Med 2017:51:64-9.

17 Greenwald RM, Gwin JT, Chu JJ, et al. Head impact severity measures for evaluating mild traumatic brain injury risk exposure. Neurosurgery 2008;62:789-98.

18 Guskiewicz KM, Mihalik JP, ShankarV, et al. Measurement of head impacts in collegiate football players: relationship between head impact biomechanics and acute clinical outcome after concussion. Neurosurgery 2007;61:1244-52.

19 Mihalik JP, Bell DR, Marshall SW, et al. Measurement of head impacts in collegiate football players: an investigation of positional and event-type differences. Neurosurgery 2007;61:1229-35.

20 Hodgson L, Patricios J. Clarifying concussion in youth rugby: recognise and remove. Br J Sports Med 2015;49:966-7.

21 Fuller GW, Kemp SP, Decq P. The International Rugby Board (IRB) Pitch side concussion assessment trial: a pilot test accuracy study. Br I Sports Med 2015;49:529-35.

22 Scorza KA, Raleigh MF, O'Connor FG. Current concepts in concussion: evaluation and management. Am Fam Physician 2012;85:123-32.

23 Doubilet PM, Cain KC. The superiority of sequential over simultaneous testing. Med Decis Making 1985;5:447-51.

24 Anon. SCAT3. Br I Sports Med 2013;47:259

25 Akobeng AK. Understanding diagnostic tests 1: sensitivity, specificity and predictive values. Acta Paediatr 2007:96:338-41.

26 Eckner JT, Kutcher JS. Concussion symptom scales and sideline assessment tools: a critical literature update. Curr Sports Med Rep 2010:9:8-15.

27 Alla S, Sullivan SJ, Hale L, et al. Self-report scales/checklists for the measurement of concussion symptoms: a systematic review. Br I Sports Med 2009;43 (Suppl 1):i3-12.
28 Yengo-Kahn AM, Hale AT, Zalneraitis BH, et al. The Sport Concussion Assessment Tool: a systematic review. Neurosurg Focus 2016;40:E6.

29 Bell DR, Guskiewicz KM, Clark MA, et al. Systematic review of the balance error scoring system. Sports Health 2011;3:287-95.

30 Hunt AW, Mah K, Reed N, et al. Oculomotor-based vision assessment in mild traumatic brain injury: a systematic review. J Head Trauma Rehabil 2016:31:252-61.

31 Galetta KM, Liu M, Leong DF, et al. The King-Devick test of rapid number naming for concussion detection: meta-analysis and systematic review of the literature. Concussion 2015;15:1-15.

32 King D, Brughelli M, Hume P, et al. Assessment, management and knowledge of sport-related concussion: systematic review. Sports Med 2014;44:449-71.

33 Maddocks DL, Dicker GD, Saling MM. The assessment of orientation following concussion in athletes. Clin J Sport Med 1995;5:32-5.

$34 \mathrm{McCrory}$ PR, Ariens T, Berkovic SF. The nature and duration of acute concussive symptoms in Australian football. Clin I Sport Med 2000;10:235-8.

35 Barr WB, McCrea M. Sensitivity and specificity of standardized neurocognitive testing immediately following sports concussion. J Int Neuropsychol Soc 2001;7:693-702.

36 Erlanger D, Kaushik T, Cantu R, et al. Symptom-based assessment of the severity of a concussion. J Neurosurg 2003:98:477-84.

37 McCrea M. Standardized mental status testing on the sideline after sport-related concussion. J Athl Train 2001;36:274-9.

38 McCrea M, Kelly JP, Randolph C, et al. Immediate neurocognitive effects of concussion. Neurosurgery 2002;50:1032-40.

39 McCrea M, Barr WB, Guskiewicz K, et al. Standard regression-based methods for measuring recovery after sport-related concussion. I Int Neuropsychol Soc 2005:11:58-69.

40 Echlin PS, Tator CH, Cusimano MD, et al. Return to play after an initial or recurrent concussion in a prospective study of physician-observed junior ice hockey concussions: implications for return to play after a concussion. Neurosurg Focus 2010;29:E5.

41 Galetta KM, Barrett J, Allen M, et al. The King-Devick test as a determinant of head trauma and concussion in boxers and MMA fighters. Neurology 2011;76:1456-62.

42 Galetta KM, Brandes LE, Maki K, et al. The King-Devick test and sports-related concussion: study of a rapid visual screening tool in a collegiate cohort. J Neurol Sci 2011;309:34-9.

43 Barr WB, Prichep LS, Chabot R, et al. Measuring brain electrical activity to track recovery from sport-related concussion. Brain Inj 2012;26:58-66.

44 King D, Clark T, Gissane C. Use of a rapid visual screening tool for the assessment of concussion in amateur rugby league: a pilot study. J Neurol Sci 2012;320:16-21.

45 Galetta MS, Galetta KM, McCrossin J, et al. Saccades and memory: baseline associations of the King-Devick and SCAT2 SAC tests in professional ice hockey players. J Neurol Sci 2013;328:28-31.

46 Dhawan PSA, Tapsell L, Adler J, et al. King-Devick test identifies symptomatic concussion in real-time and asymptomatic concussion over time. Neurol Clin Pract 2014;82:S11.

47 Leong DF, Balcer LJ, Galetta SL, et al. The King-Devick test as a concussion screening tool administered by sports parents. J Sports Med Phys Fitness 2014;54:70-7.

48 Galetta KM, Morganroth J, Moehringer N, et al. Adding vision to concussion testing: a prospective study of sideline testing in youth and collegiate athletes. I Neuroophthalmol 2015:35:235-41.

49 Leong DF, Balcer LJ, Galetta SL, et al. The King-Devick test for sideline concussion screening in collegiate football. J Optom 2015;8:131-9.

50 Marinides Z, Galetta KM, Andrews CN, et al. Vision testing is additive to the sideline assessment of sports-related concussion. Neurology 2015;5:25-34.

51 Putukian M, Echemendia R, Dettwiler-Danspeckgruber A, et al. Prospective clinical assessment using sideline Concussion Assessment Tool-2 testing in the evaluation of sport-related concussion in college athletes. Clin J Sport Med 2015;25:36-42.

52 Seidman DH, Burlingame J, Yousif LR, et al. Evaluation of the King-Devick test as a concussion screening tool in high school football players. J Neurol $\mathrm{SC}$ 2015;356:97-101. 